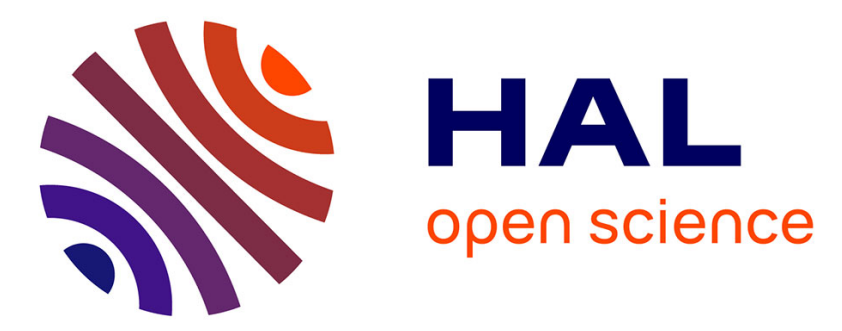

\title{
13 metastable states arising from a simple multifunctional unimolecular system
}

Lionel Sanguinet, Jérôme Berthet, György Szalóki, Olivier Alévêque, Jean-Luc Pozzo, Stéphanie Delbaere

\section{- To cite this version:}

Lionel Sanguinet, Jérôme Berthet, György Szalóki, Olivier Alévêque, Jean-Luc Pozzo, et al.. 13 metastable states arising from a simple multifunctional unimolecular system. Dyes and Pigments, 2017, 137, pp.490 - 498. 10.1016/j.dyepig.2016.10.027 . hal-01655150

\section{HAL Id: hal-01655150 \\ https://hal.science/hal-01655150}

Submitted on 20 Feb 2020

HAL is a multi-disciplinary open access archive for the deposit and dissemination of scientific research documents, whether they are published or not. The documents may come from teaching and research institutions in France or abroad, or from public or private research centers.
L'archive ouverte pluridisciplinaire HAL, est destinée au dépôt et à la diffusion de documents scientifiques de niveau recherche, publiés ou non, émanant des établissements d'enseignement et de recherche français ou étrangers, des laboratoires publics ou privés. 


\section{Accepted Manuscript}

13 metastable states arising from a simple multifunctional unimolecular system

Lionel Sanguinet, Jérôme Berthet, György Szalóki, Olivier Alévêque, Jean-Luc Pozzo,

Stéphanie Delbaere

PII: S0143-7208(16)30853-1

DOI: $\quad$ 10.1016/j.dyepig.2016.10.027

Reference: DYPI 5543

To appear in: Dyes and Pigments

Received Date: 28 September 2016

Revised Date: 19 October 2016

Accepted Date: 21 October 2016

Please cite this article as: Sanguinet L, Berthet J, Szalóki G, Alévêque O, Pozzo J-L, Delbaere S, 13 metastable states arising from a simple multifunctional unimolecular system, Dyes and Pigments (2016), doi: 10.1016/j.dyepig.2016.10.027.

This is a PDF file of an unedited manuscript that has been accepted for publication. As a service to our customers we are providing this early version of the manuscript. The manuscript will undergo copyediting, typesetting, and review of the resulting proof before it is published in its final form. Please note that during the production process errors may be discovered which could affect the content, and all legal disclaimers that apply to the journal pertain. 

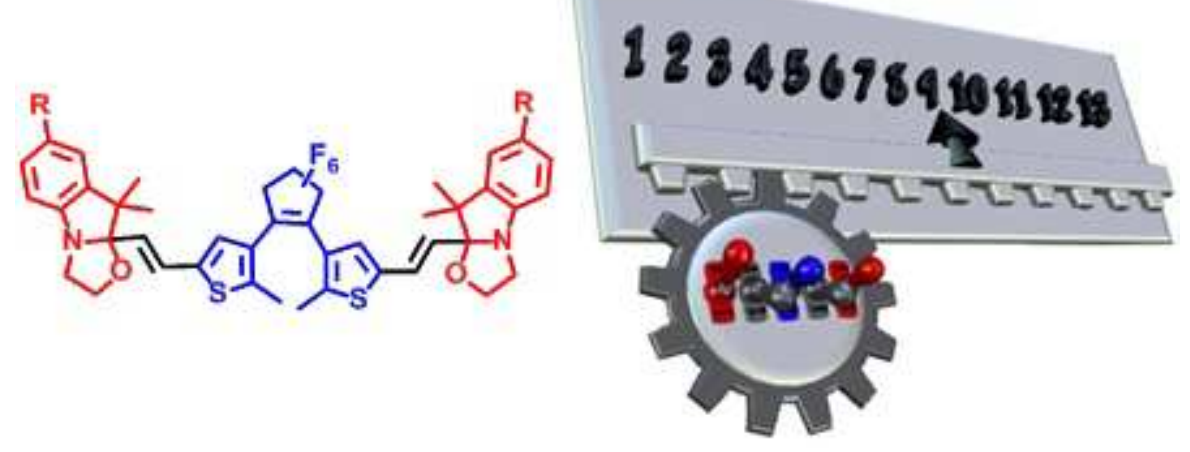


\section{3 metastable states arising from a simple multifunctional}

\section{unimolecular system}

Lionel Sanguinet ${ }^{a,}{ }^{*}$, Jérôme Berthet $^{\mathrm{b}}$, György Szalóki ${ }^{\mathrm{a}}$, Olivier Alévêque ${ }^{\mathrm{a}}$, Jean-Luc Pozzo ${ }^{\mathrm{c}}$, Stéphanie Delbaere ${ }^{\mathrm{b}, *}$

a Laboratoire MOLTECH-Anjou, Université d'Angers, CNRS-UMR 6200, 2 boulevard Lavoisier, 49045 Angers Cedex, France.

b Universite Lille, CNRS UMR 8516, LASIR, Laboratoire de Spectrochimie et Raman, BP83, F-59006 Lille, France

c Institut des Sciences Moléculaires, Université Bordeaux, 351 Cours de la Libération, 33405, Talence, France

stephanie.delbaere@univ-lille2.fr

lionel.sanguinet@univ-angers.fr

KEYWORDS: Photochromism, acidochromism, electrochromism, Diarylethene, Benzooxazolidine

ABSTRACT: A diarylethene core decorated with two benzooxazolidine side-arms through ethylenic spacers represents a smart example of multi-addressable system whose reversible responses could be selectively activated on demand. UV-Visible and NMR spectroscopies 
and electrochemical studies allow to overview its performances when stimulated by light, acid/base and electrons, then underlining its photochromic, acidochromic and electrochromic properties. The multichromophoric combination could be considered as multifunctional and multistate systems, as interconversions can be performed by different stimuli whereas each stimulus provides a specific metastable state.

\section{Introduction.}

Photochromic diarylethenes possessing reversible sets of physicochemical properties have been largely exploited for applications such as switches, rectifiers and memories [1-3]. In fact, their excellent photochromic performances encompassing fatigue resistance, short time response, high quantum yields and no thermal isomerization, ensure to switch upon irradiation between colorless and closed colored forms which exhibit different properties. Furthermore, diarylethenes have been reported to exhibit electrochromic behavior performing cyclisation/ ring opening by application of an electrochemical potential [4-6]. Indolino[2,1b]oxazolidine derivatives [7-9] belong to a more recent family of photochromic dyes displaying multimodal photo- and acidochromic properties. In addition, the substitution of an indolino[2,1b]oxazolidine unit with a bithiophene redox probe generated a system capable to be commuted reversibly and indifferently either under UV irradiation, acidity changes or electrochemical stimulation, and thus, confers to this molecular system a pretty and uncommon trimodal switching behavior. [10]

In this context, the combination of diarylethene and indolino-oxazolidine units through covalent linkers offers a multi-addressable system expected to provide up to $2^{\text {n }}$ distinct states (with $\mathrm{n}$ the number of addressable units). The main challenge of such system is not only to keep the selective and controlled addressing of individual units but also to find the right 
equilibrium between multifunctional (the same interconversion can be performed by different stimuli) and multistate (each stimulus provides a specific metastable state) properties.

The present paper deals with the design and the investigation of the behavior of a novel molecular system 1 associating the two types of photochromic compounds through ethylenic junction (Scheme 1) and its bis-methyl substituted derivative 2. As consequence, the presence of five addressable units should lead to $2^{5}$ different states according to the closed or open forms of indolino-oxazolidine, associated with trans or cis ethylenic junction to the open or cyclized diarylethene and excluding the absolute stereochemistry of the molecular system (due to the presence of an asymmetric carbon atom in the closed forms of indolinooxazolidine). The 32 possible states are reduced to 18 due to symmetry consideration. Each unit exhibiting different and complementary multimodal switching abilities, their association should lead to the development of a promising molecular multistate system where the individual units could be selectively addressed by selecting the appropriate stimulation (light, chemicals, and electron). This keypoint is particularly relevant for molecular memory or logic gate operators [11-14]. As a consequence of their mutual influence, the commutation of the different addressable units is expected to induce a drastic change of the optical properties of the whole molecular system. In this context, the UV-Visible absorption spectroscopy is certainly the simplest characterization technique to monitor the different commutation states under various stimuli. In parallel, NMR spectroscopy offers an elegant way to structurally characterize the various isomers. 

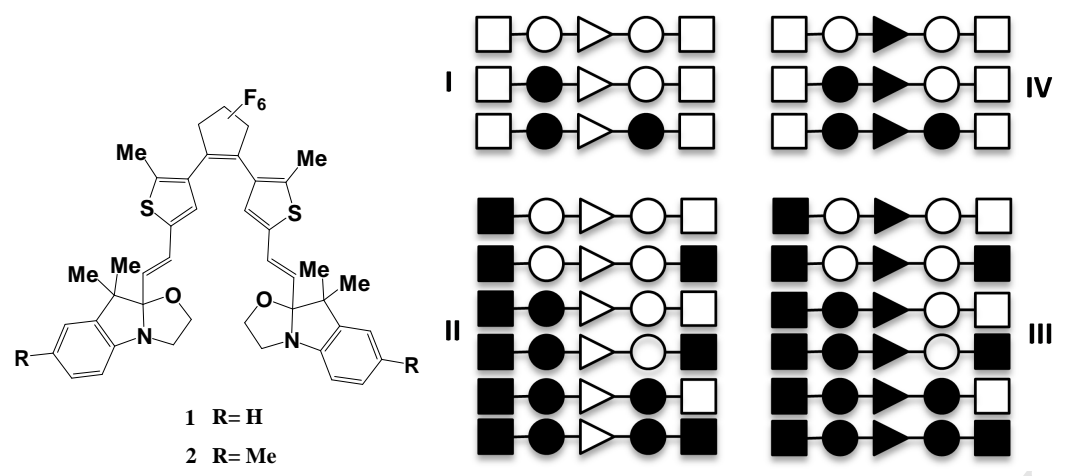

Scheme 1. Target compounds 1 and 2 and the eighteen possible combinations ( $\square$ Box, $\bigcirc$

$$
\mathrm{C}=\mathrm{C}, \triangleright \mathrm{DAE})
$$

\section{Results and discussion.}

2.1 Investigations of processes between all-trans isomers of targets in their initial state Itt Addition of trifluoroacetic acid (TFA) in $\mathrm{CH}_{3} \mathrm{CN}$ solution of target 1 (2) in its initial state Itt induced the opening of both oxazolidine rings into the corresponding protonated form lltt (See scheme 2 for structures of states) concomitantly with color change of solution from colorless to yellow (Figure 1, 1; data for $\mathbf{2}$ are in supplementary materials). The successive addition of some acid aliquots revealed an isosbestic point evidencing that the oxazolidine ring opening did not occur in a stepwise manner. Indeed, under their closed forms, the indoline heterocycles are generally almost orthogonal to their olefinic substituent [15-16]. As a consequence, no interaction through bonds between them could be expected leading to an independent behavior and then a concomitant commutation of them when the indolinooxazolidine units, hereafter named BOX for convenience, are directly stimulated. Absorption band is bathochromically shifted to $442 \mathrm{~nm}(443 \mathrm{~nm})$ with a concomitant decrease of the band at $280 \mathrm{~nm}$, translating the extension of the $\pi$ conjugated system and the establishment of a charge transfer band between thienyl donor and indoleninium acceptor parts. The indoleninium moities $\left(\mathrm{N}-\mathrm{CH}_{2}-\mathrm{CH}_{2}-\mathrm{OH}\right)$ are clearly identified by two well-resolved triplets at 4.0 
and 4.6 ppm in ${ }^{1} \mathrm{H}$ NMR spectrum, characterizing lltt, having its ethylenic junctions in trans isomery, as indicated by the two doublets at $7.2(\mathrm{I}=2 \mathrm{H})$ and $8.4(\mathrm{I}=2 \mathrm{H})$ ppm with a vicinal scalar coupling of $15.9 \mathrm{~Hz}$ (Figure 2). Closure of BOX units upon neutralization with triethylamine (TEA) vapor was confirmed by the disappearance of absorption band at $442 \mathrm{~nm}$ and the initial absorption spectrum was recovered entirely. This was nicely evidenced by NMR studies where a concomitant disappearance of triplet signals at 4.0 and $4.6 \mathrm{ppm}$ and the reappearance of $\mathrm{CH}_{2}$ signals for closed $\mathrm{BOX}$ between 3.3 and $3.8 \mathrm{ppm}$ were observed. Consequently, the stimulation of the system by $\mathrm{pH}$ change allows to switch between states Itt and Iltt in a selective, quantitative and reversible manner.

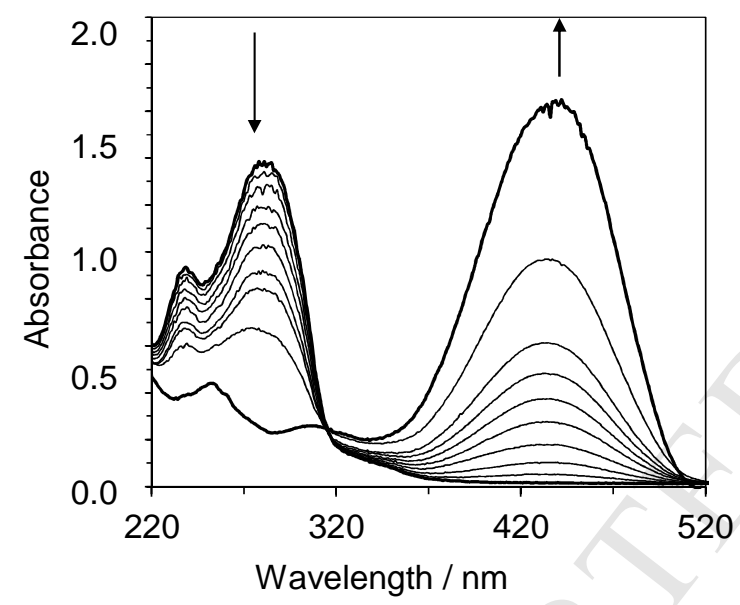

Figure 1. Absorption changes Itt $\rightarrow \mathrm{Iltt}\left(\mathbf{1}, 2.5 \times 10^{-5} \mathrm{M}, \mathrm{CH}_{3} \mathrm{CN}\right)$ upon acid addition. 

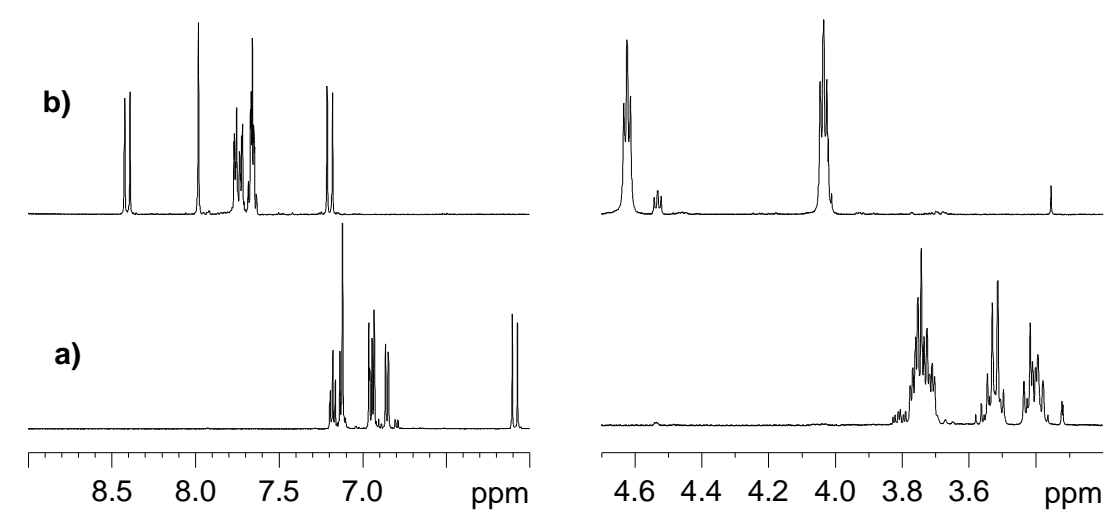

Figure 2. ${ }^{1} \mathrm{H}$ NMR spectrum a) of state Itt b) of state Iltt $\left(1,10^{-3} \mathrm{M}, \mathrm{CD}_{3} \mathrm{CN}\right)$.

Both DAE and BOX exhibit photochromic behavior, nevertheless irradiation of target 1 (2) in its initial state Itt in acetonitrile with $254 \mathrm{~nm}$ or $312 \mathrm{~nm}$ light conducts to selective cyclization of the diarylethene unit (abbreviated as DAE) as supported by the appearance of a band at 585 $\mathrm{nm}(583 \mathrm{~nm})$, and the concomitant decrease of the band at $280 \mathrm{~nm}(285 \mathrm{~nm})$ (Figure 3). This process is accompanied by a color change of solution from colorless to blue. From ${ }^{1} \mathrm{H}$ NMR spectrum, $90 \%$ of conversion is quantified from the $\mathrm{CH}_{3}$ and the thienyl ${ }^{1} \mathrm{H}$ signals shifted from 1.95 to $2.1 \mathrm{ppm}$, and from 7.1 to $6.5 \mathrm{ppm}$, respectively, evidencing the cyclization of DAE in IVtt (Figure 4). State IVtt is thermally stable for weeks at ambient temperature, while bleached completely back to colorless solution with visible light $(577 \mathrm{~nm})$ irradiation.

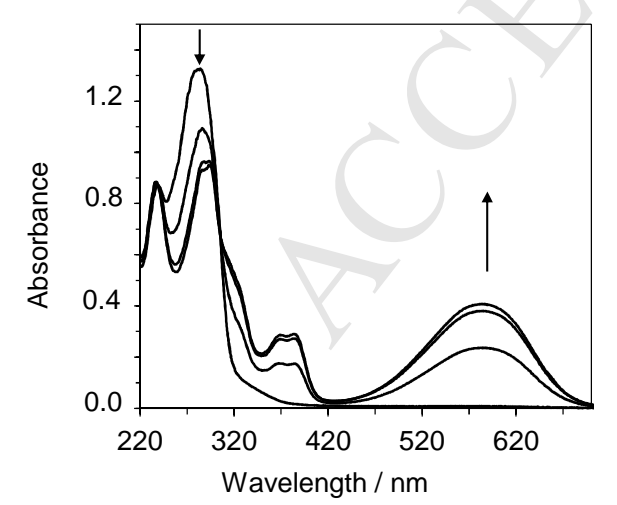

Figure 3. Absorption changes Itt $\rightarrow \mathrm{IVtt}\left(\mathbf{1}, 2.5 \times 10^{-5} \mathrm{M}, \mathrm{CH}_{3} \mathrm{CN}\right)$ upon $312 \mathrm{~nm}$ light irradiation. 


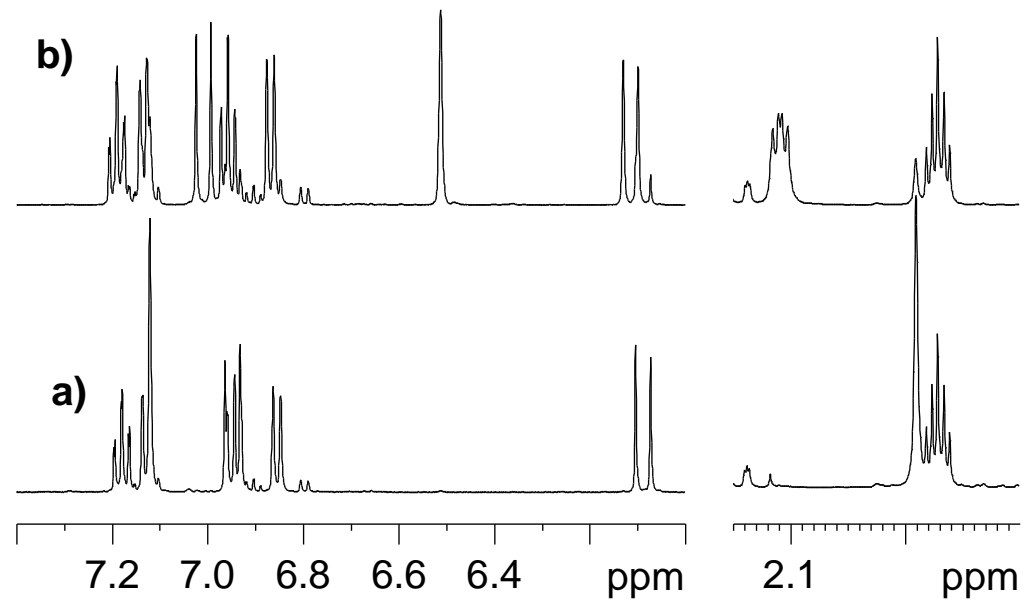

Figure 4. ${ }^{1} \mathrm{H}$ NMR spectrum a) of state Itt b) of state IVtt $\left(\mathbf{1}, 10^{-3} \mathrm{M}, \mathrm{CD}_{3} \mathrm{CN}\right)$.

Consequently, the stimulation of the system by UV then Visible light induces the switch between the states Itt and IVtt in a selective, almost quantitative and reversible manner. Whatever the wavelength selected no traces of photoinduced ring-opening of BOX accompanied the DAE cyclization. To stimulate the BOX motif, chlorobenzene was added as a photo-sensitizer [7,17]. Irradiation with $254 \mathrm{~nm}$ light of state Itt in acetonitrile/chlorobenzene (90/10) solution reveals the appearance of new bands in 420-440nm range (open BOX, lltt) and in 580-600 nm (cyclized DAE, IVtt) (Figure 5). When irradiation time is prolonged, the band characterizing cyclized DAE is shifted into a new band in 700-770 nm area. The same experiment was repeated and followed by NMR spectroscopy, confirming the transformation of state Itt into states IItt and IVtt, the latter being then converted into state III'tt, with only one of the BOX in open configuration. This means that addressability of I by $254 \mathrm{~nm}$ light in acetonitrile/chlorobenzene solution is not selective as it conducts to a mixture of states (IItt, IVtt and III'tt). 


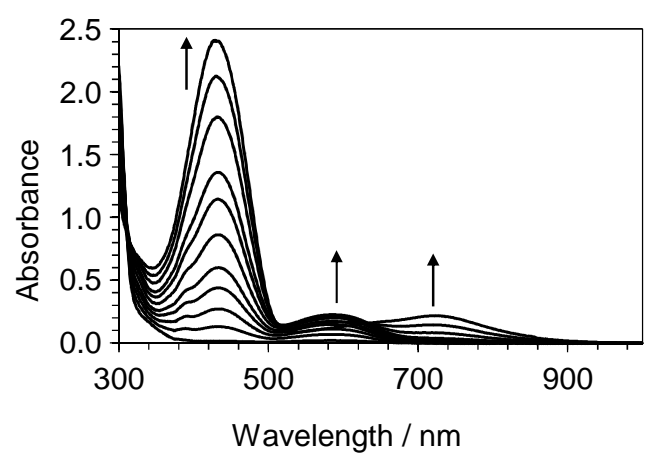

Figure 5. Absorption changes Itt $\rightarrow$ Iltt+IVtt(+III'tt) $\left(1,2.5 \times 10^{-5} \mathrm{M}, \mathrm{CH}_{3} \mathrm{CN} / \mathrm{CIPh}\right)$ upon 254nm light irradiation.

This selective addressability issue can be circumvented by changing the nature of the stimulation to acidity conditions (vide supra) or by applying irradiation wavelengths within an appropriate sequence. In a first step, $312 \mathrm{~nm}$ light was applied to acetonitrile/chlorobenzene solution of targets leading selectively to the DAE cyclisation (Itt $\rightarrow \mathbf{I V t t}, 90 \%, \lambda=590 \mathrm{~nm})$. Clearly, no typical signals for the open oxazolidine ring or for the $E / Z$ isomerization of double bond can be detected. In a second step, the BOX units of IVtt were activated following two different ways: i) by acid addition leading to a color change of the solution from blue to green, characterizing the appearance of the state IIItt (both BOX are open) whose absorption bands are centered at 450 and $780 \mathrm{~nm}$ for target 1 (455 and $773 \mathrm{~nm}$ for 2) (Figure 6a). 

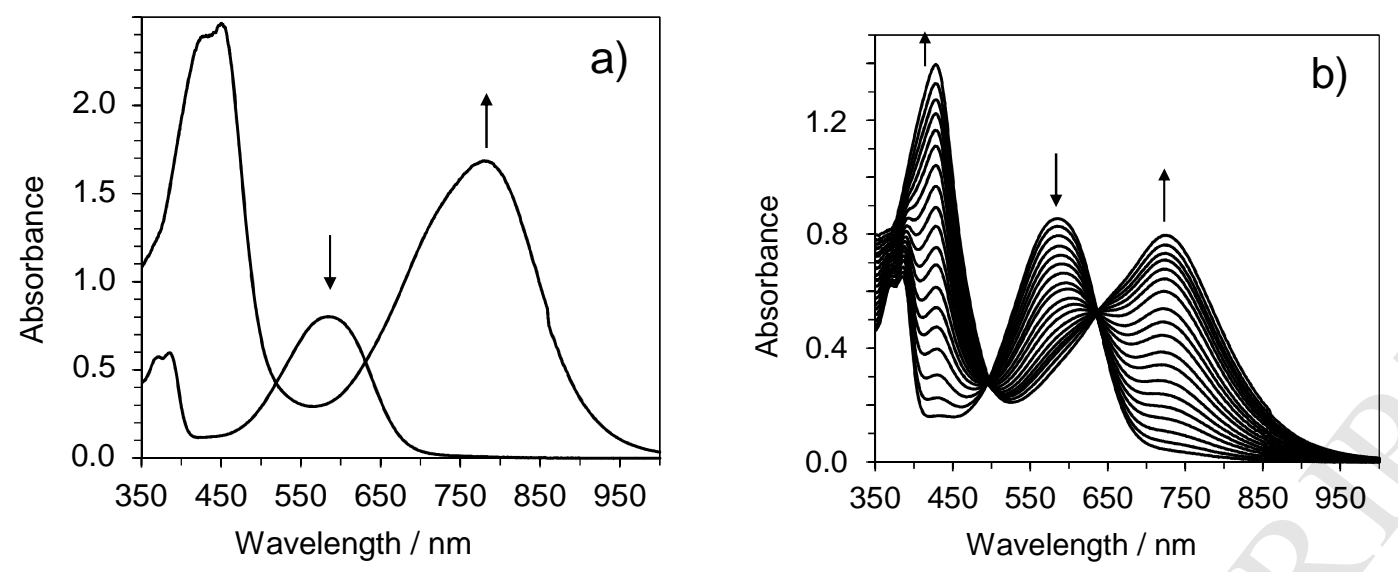

Figure 6. Absorption changes $\left(\mathbf{1}, 2.5 \times 10^{-5} \mathrm{M}, \mathrm{CH}_{3} \mathrm{CN} / \mathrm{ClBz}\right)$ a) IVtt $\rightarrow$ IIItt upon acid addition b) IVtt $\rightarrow$ III'tt upon $254 \mathrm{~nm}$ light irradiation.

The simultaneous opening of both oxazolidine rings is well confirmed by NMR spectroscopy with the $\mathrm{CH}_{2}$ triplet signals at 3.85 and $4.55 \mathrm{ppm}$ (open $\mathrm{BOX}$ ) and the $\mathrm{CH}_{3}$ signal at $2.25 \mathrm{ppm}$ (Cyclized DAE). ii) by irradiation with $254 \mathrm{~nm}$ light of state IVtt in presence of chlorobenzene, inducing a strong bathochromic shift of the absorption bands (Figure 6b). More important, the opening of the two BOX units is no anymore simultaneous but occurs in stepwise manner when the DAE is closed. It is clearly indicated by the appearance of new absorption bands centered at 428 and $723 \mathrm{~nm}$ (432 and $722 \mathrm{~nm}$ for 2) with a concomitant decrease of the absorption at $585 \mathrm{~nm}$ (582 nm for 2), and the clear evidence of isosbestic points supporting the presence of only two species state IVtt and state III'tt (cyclized DTE with one open and one closed BOX). When the duration of irradiation is prolonged, a bathochromic shift of the band at lower energy followed by a rapid decrease of its absorption intensity, while a continuous increase and hypsochromic shift of the band at higher energy are observed. The shape modification accompanied by the absence of isosbestic point let presume that if the opening of the second BOX occurs well leading to the state Illtt (cyclized DTE with two open 
BOX), the stability of this last one is limited in our experimental conditions. Indeed, while similar compounds associating the DAE unit with one BOX unit showed no thermal evolution [18-19], here the substitution with two open BOX leads to a slow thermal opening of DAE as observed by UV and NMR spectroscopy $\left({ }^{293} \mathrm{k}_{\Delta}=5.3 \times 10^{-5} \mathrm{~s}^{-1}\right)$ towards state lltt. Then, the restoration of the molecular system under its initial state Itt can be achieved : from IIItt or IIl'tt upon base treatment leading to IVtt, then bleached with visible light, or from IIItt upon thermal relaxation leading to II, then neutralized with base.

As a consequence, the status of the central DAE moiety strongly influences the photochemical behavior of the BOX units. When DAE is open (State Itt), irradiation in presence of chlorobenzene with $254 \mathrm{~nm}$ light activates the simultaneous opening of both BOX units (State IItt). In contrast, when DAE is cyclized (State IVtt), stepwise opening of BOX occurred (States IIItt and III'tt). In the same way, the response of the DAE unit is dependent on the BOX status. In fact, all attempts to cyclize the DAE when both BOX are open (state Iltt) using UV light at different wavelengths were unsuccessful. Contrary to previous investigations on various DAE substituted with one BOX unit where the photocyclization efficiency of diarylethene is strongly reduced by the status of BOX, here, its photochromic behavior is totally suppressed with both open BOX. In resume, the different evidenced interconversions between the all-trans states are displayed in Scheme 2. 


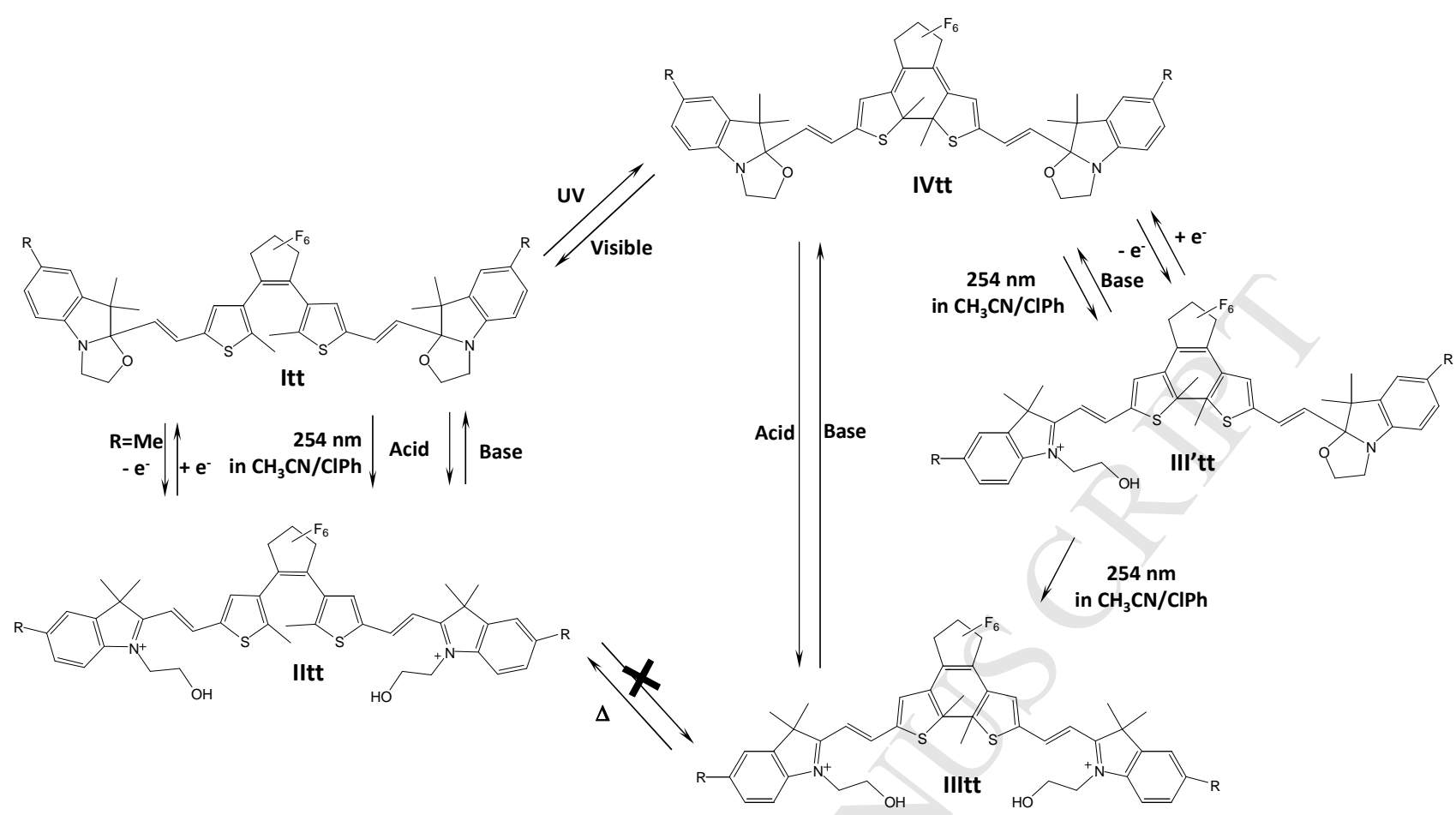

Scheme 2. Reaction pathway between all-trans isomers

2.2 Investigations of processes between cis isomers of targets

Based on previous investigations on similar molecular system [18,19], the photo-isomerization of the ethylenic junction between BOX and DAE is expected, especially when the pending BOX is open. In this context, the trans-cis isomerization of both ethylenic junctions has been studied by ${ }^{1} \mathrm{H}$ NMR spectroscopy. When the state Iltt is generated from initial state Itt (previously shown to have all-trans junctions), both ethylenic junctions exhibit a trans geometry, as clearly evidenced by two doublets at 7.2 and 8.4 ppm with a scalar coupling constant of $15.8 \mathrm{~Hz}$. Under UV light (254 or $313 \mathrm{~nm}$ ) no cyclization of DAE from Iltt to Illtt occurred, but trans-cis isomerization of the ethylenic bonds was observed, and was more efficient when UV is replaced by visible light $(\lambda>400 \mathrm{~nm})$. The state Iltt is then photo- 
transformed into two isomers: Ilct (20\% at PSS; isomerization of only one ethylenic bridge) characterized by four doublets $\left(7.1\right.$. and $8.4 \mathrm{ppm}$ with ${ }^{3} \mathrm{~J}=15.8 \mathrm{~Hz}$, and 6.5 and $7.5 \mathrm{ppm}$ with ${ }^{3} \mathrm{~J}=13 \mathrm{~Hz}$ ) and IIcc $(70 \%$ at PSS; isomerization of both ethylenic bridges) characterized by two doublets $\left(6.45(\mathrm{I}=2 \mathrm{H})\right.$ and $7.45(\mathrm{I}=2 \mathrm{H})$ ppm with $\left.{ }^{3} \mathrm{~J}=13 \mathrm{~Hz}\right)$. These two isomers with at least one cis-isomery bond relaxed thermally into the state $\|$ litt $\left(k_{\text {Ilcc } \rightarrow \text { llct }}=910^{-4} \mathrm{~s}^{-1}\right.$ and $\mathrm{k}_{\text {Ilct } \rightarrow \text { lltt }}$ $=510^{-4} \mathrm{~s}^{-1}$ at rt). As expected, these two cis-isomers of state II (Ilct and Ilcc) can also be neutralized with TEA leading to the closing of BOX into the corresponding states Ict and Icc. In contrast, they are photochemically silent, as no irradiation enabled to cyclize the diarylethene unit. Concerning the two cis-isomers of state I (Ict and Icc), they evolved very

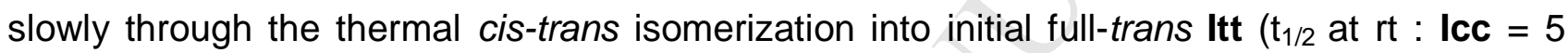
days; Ict $=10$ days). When they are submitted to UV irradiation, the cyclization of DAE (Ict $\rightarrow$ IVct and Icc $\rightarrow$ IVcc) is induced. The two isomers IV with at least one cis-isomery bond relaxed thermally into the state $\mathbf{I V t t}\left(\mathrm{k}_{\mathrm{IVcc}_{\rightarrow} \mathrm{IVct}}=310^{-4} \mathrm{~s}^{-1}\right.$ and $\mathrm{k}_{\mathrm{IVct} \rightarrow} \mathrm{IVtt}=1.510^{-4} \mathrm{~s}^{-1}$ at $\left.\mathrm{rt}\right)$. Surprisingly, upon acid addition on cis-isomers of state IV (IVcc + IVct), the state IIltt was directly detected while its corresponding cis isomers (IIIcc + IIIct) would have been expected. They were not observed probably due to a high thermal instability. It should be also noted that the reverse reaction of trans-cis isomerization from Illtt was never observed whatever the stimulus used.

From this study, we can conclude that all the states having at least one ethylenic junction in cis isomery present a thermal reversibility and no photoreaction occurred between the states II and III. The set of processes between all cis-states is summarized in Scheme 3. 


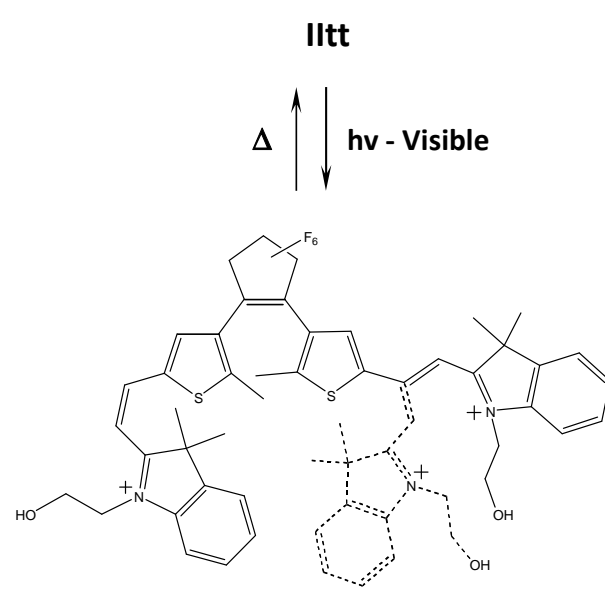

Ilct/IIcc

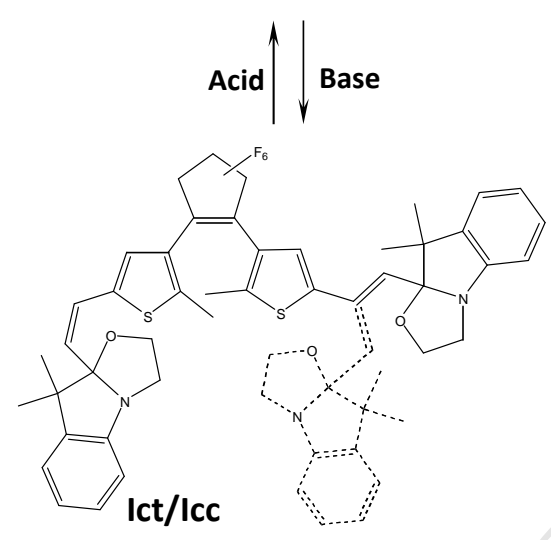

$\Delta \downarrow$

Itt
IIItt

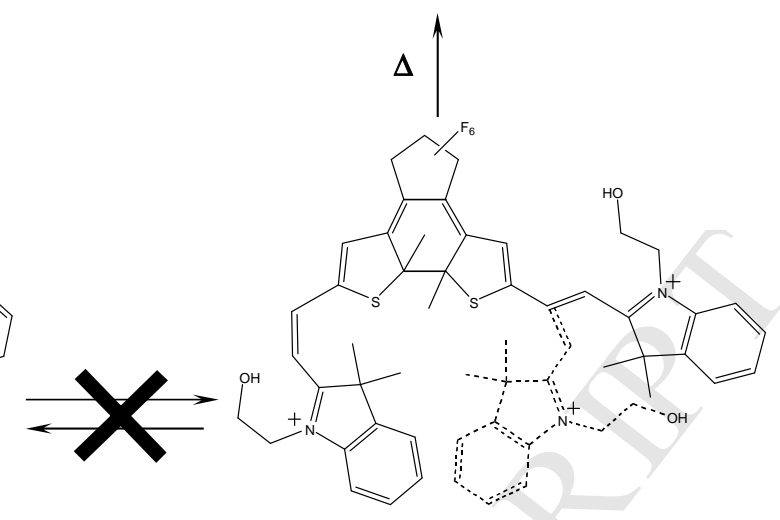

IIIct/IIIcc

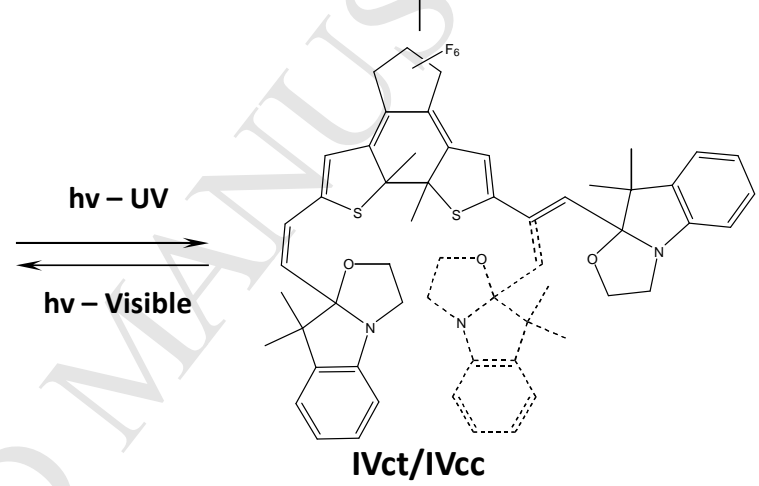

$\Delta \downarrow$

IVtt

Scheme 3. Reaction pathway between cis isomers

\subsection{Electrochromic response of targets}

BOX [10,20] and DAE [4-6] units can also be electrochemically addressed. These electroinduced behaviors represent an additional and alternative way to stimulate them selectively. In this context, the electrochemical behaviors of $\mathbf{1}$ and $\mathbf{2}$ were investigated by cyclic voltammetry $(\mathrm{CV})$. The $\mathrm{CV}$ of both compounds under their initial state Itt reveal one irreversible oxidation process at 0.78 and $0.77 \mathrm{~V}$ for compounds 1 and 2 (Figure 7a-b) 
respectively and are assigned to the oxidation of the BOX units. As previously observed [20], this oxidation conducts, when no substituent is present in position 5 of the indoline heterocycle (Target 1), to a $\mathrm{C}-\mathrm{C}$ oxidative coupling between $\mathrm{BOX}$ unit either in an intra or intermolecular manner and translated on the $\mathrm{CV}$ by the emergence of new redox systems at lower potential $(0.46 \mathrm{~V})$ on the scan back (Figure $7 \mathrm{a})$. This assumption is clearly confirmed by spectroelectrochemistry experiment. In fact, once the oxidation potential reaches $0.78 \mathrm{~V}$, one absorption band centered at $494 \mathrm{~nm}$ appears, being the spectral signature of the formation of the oxidized BOX dimer [20] (Figure 7c).
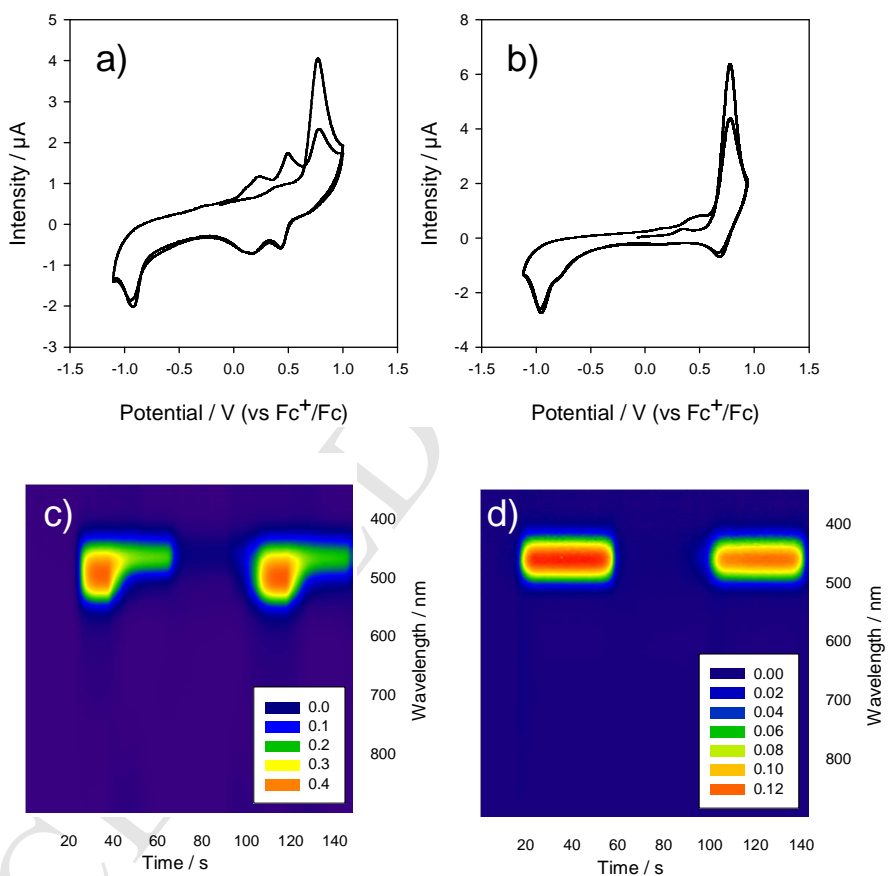

Figure 7. Thin layer cyclic voltammetry of a) $\mathbf{1}$ b) $\mathbf{2}$, and corresponding spectroelectrochemistry of c) $\mathbf{1}$ d) $\mathbf{2}$, in ACN under state Itt.

At the opposite, the presence of a methyl group (Target 2) avoids the C-C oxidative coupling, then permitting the electroinduced ring opening of the oxazolidine as evidenced by the 
irreversibility of oxidation process at $0.77 \mathrm{~V}$ and any appearance of new signal at lower potential (Figure $7 \mathrm{~b}$ ). Moreover, the electrochemical oxazolidine opening is confirmed by the spectro-electrochemical experiment. Indeed, an absorption band at $460 \mathrm{~nm}$ is generated when reaching $0.77 \mathrm{~V}$ as oxidation potential (Figure $7 \mathrm{~d}$ ). Subsequent reduction of the system at $-0.96 \mathrm{~V}$ restores the initial state. As a consequence, the electrostimulation of the target 2 allows to switch between states Itt and Iltt in a reversible manner as confirmed by the spectro-electrochemical experiments with the successive appearance and disappearance of the absorption band at $460 \mathrm{~nm}$ as function of the electrochemical potential.

The electrochemical properties of both targets under their state IVtt (generated initially by UV irradiation of state Itt with $312 \mathrm{~nm}$ light to photocyclize the DAE unit) were also studied. A strong cathodic shift of the first oxidation potential is observed to reach ca. 0.61 and $0.63 \mathrm{~V}$ for 1 and 2 respectively (Figure 8), whatever the substitution pattern is, and thus, is assigned to the oxidation of the DAE core in agreement with previous studies on electrochemical behavior of various DAE derivatives [5-6]. 

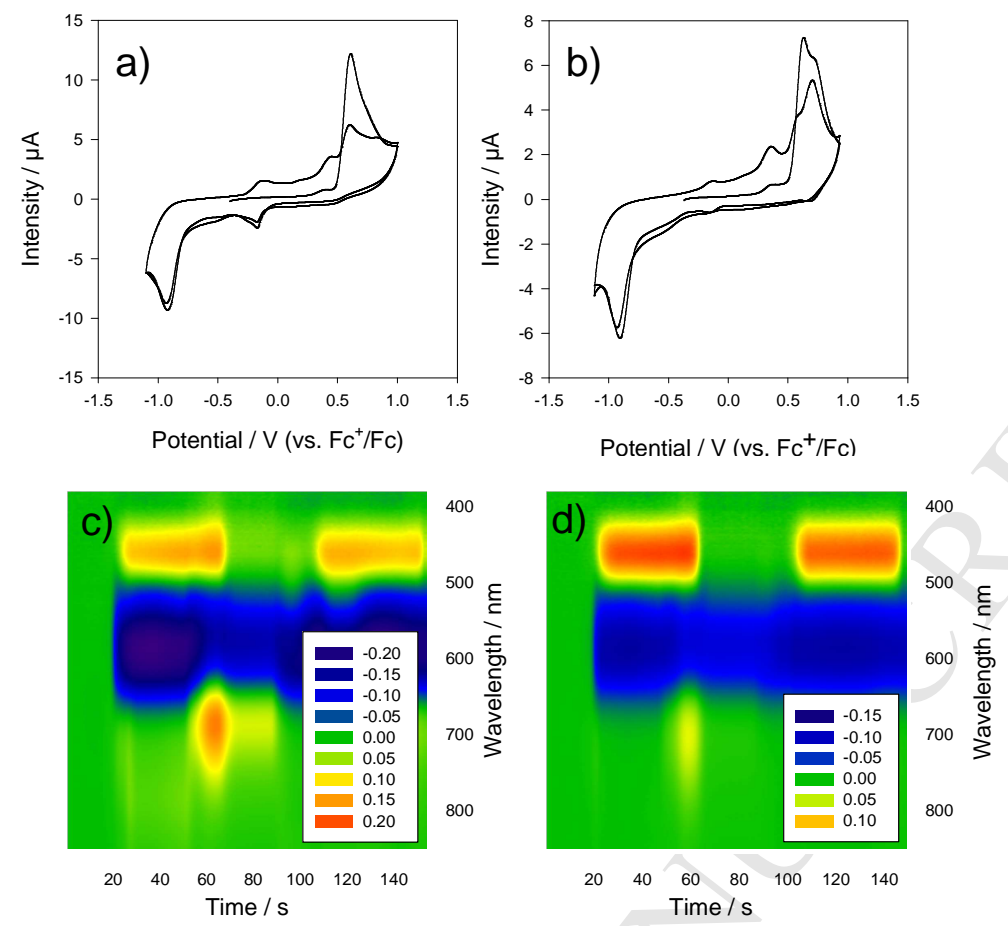

Figure 8. Thin layer cyclic voltammetry of a) $\mathbf{1}$ and b) $\mathbf{2}$, and spectroelectrochemistry experiment of c) $\mathbf{1}$ and d) 2 , under the state IVtt with TBAP as electrolyte at $20 \mathrm{mV} / \mathrm{s}$ on Pt.

When the positive charges are not efficiently stabilized, the generation of closed dicationic DAE leads generally to the opening of the DAE which is translated on CV by an irreversible oxidation process [5-6] and the appearance of a signal at higher potential corresponding to the oxidation of the open form of DAE. In the present study, the oxidation of the state IVtt conducts to the appearance of a new redox system at lower potential $(-0.14 \mathrm{~V}$ for $\mathbf{1}$ and $0.11 \mathrm{~V}$ for 2) that could result from the opening of one BOX unit. In fact, some of us have recently demonstrated that the electrochemical stimulation of a redox probe associated to a BOX such as a bithiophene induced the oxazolidine ring opening [10]. In order to verify this assumption, the electrochemical properties of $\mathbf{1}$ under the state III'tt (prepared by irradiation of Itt with $312 \mathrm{~nm}$ light $(\mathbf{I} \rightarrow \mathbf{I V})$, then with $254 \mathrm{~nm}$ light $(\mathbf{I V t t} \rightarrow \mathrm{III}$ 'tt $)$ in 
acetonitrile/chlorobenzene) were studied. The CV (Figure 9a/b) exhibit a reversible oxidation process at $-0.14 \mathrm{~V}$, then supporting the electrochemical opening of one oxazolidine ring via the oxidation of the central DAE unit observed previously. Moreover, this assumption is nicely confirmed by the spectroelectrochemistry experiments (Figure $8 \mathrm{c} / \mathrm{d}$ ) with the successive disappearance of the band characteristic of the state IVtt (585 and 593nm for compounds 1 and 2 respectively) and the appearance of the band corresponding to the state III'tt (428/723 $\mathrm{nm}$ and 432/722 $\mathrm{nm}$ for compounds 1 and 2 respectively). In addition, the irreversible reduction at -0.920 et $-0.911 \mathrm{~V}$ for $\mathbf{1}$ and $\mathbf{2}$, leads to the disappearance of these characteristic bands, translating as expected the closure of the oxazolidine ring towards the state IVtt under electrochemical stimulation, as previously observed with the process of closing from lltt to ltt.

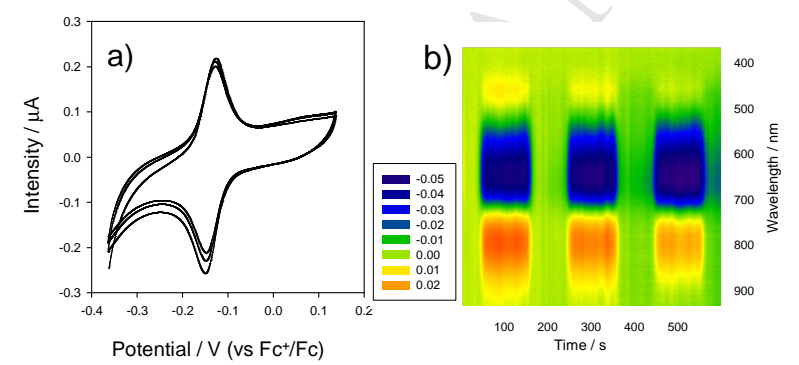

Figure 9. a) Thin layer cyclic voltammetry and b) corresponding spectroelectrochemistry experiment of 1 previously irradiated at $313 \mathrm{~nm}$ then at $254 \mathrm{~nm}$ (state III'tt).

However, the corresponding oxidized species of the state IIl'tt present a strong instability in our experimental conditions especially when higher potential is applied. At the time scale of the electrochemistry experiments, this instability (larger with 2 than with 1 ) results to the opening of the central DAE moiety as confirmed by the increase of the absorption intensity at $460 \mathrm{~nm}$. The hypothesis that the oxidation of the state III'tt induces the opening of the second BOX unit providing the state IIItt then after relaxes into state lltt as observed by UV and NMR 
spectroscopy is not consistent with electrochemical data. First, the spectro-electrochemical experiment performed on the state III'tt obtained photochemically reveals some absorption variations which are not matching with the state Illtt. Second, opening of the second BOX unit requests the formation of a radical cation on the central DAE which is not consistent with general effect of the substituent nature on redox potential. In fact, the opening of one BOX unit leading to the formation of an indoleninium moiety acting as strong electron withdrawing group, leads to an impressive cathodic shift (almost $500 \mathrm{mV}$ ). However, such an unexplained cathodic shift was already observed on DAE. In 2005, Browne et al. studied the electrochemical behavior on various substituted DAE and reported the existence of a competitive oxidation process to the classical oxidation of cyclized form (at $-0.1 \mathrm{~V}$ for the 5 -( $p$ methoxyphenyl)-5'-phenyl-perfluoroDAE as example) leading to an unknown species referenced as $\mathrm{X}$ form. [5,6]. As consequence, we can presume that an identical process occurs here. The authors suggested that the $\mathrm{X}$ intermediate results from a reversible intramolecular rearrangement of the dicationic species of the closed form into a more stable species which would explain its appearance only on the scan back of the closed form oxidation and its irreversibility. At the opposite, we can observe the reversible oxidation of this intermediate in solution of compound $\mathbf{1}$ under the state III'tt obtained by successive irradiation at 313 then $254 \mathrm{~nm}$. This fact lets us envisage its formation directly from the neutral closed DAE and strongly correlated to the donor or acceptor nature of the substituent borne by the DAE unit. As consequence, the complete clarification and understanding of the formation of this $\mathrm{X}$ form request deeper investigation. 


\section{Conclusions.}

The designed targets incorporate five addressable units which could generate up to 32 different states, constituting the most sophisticated system to date. However, their number is here restricted to eighteen due to the symmetrical substitution of the diarylethene central unit. In the present work, we have demonstrated that thirteen of them can be effectively produced and detected. The way to access to each of them was also extracted by playing with selected stimuli on the multimodal properties of the system, such as light with specific wavelengths associated with the nature of solvent (Photochromism), $\mathrm{pH}$ variation (acidochromism), temperature (thermochromism) and electrons (electrochromism). Thus, the present target represents a nice example of system having multifunctional and multistate properties. In addition, a gated photochromism of the DAE unit was underlined. Indeed, the photoinduced cyclization with UV light of DAE from its open form towards the closed one $(I \rightarrow I V)$ is selective and almost quantitative in acetonitrile solution when the BOX units are closed and the reverse reaction is achieved with visible light. Once BOX are open, the photochromism properties of the DAE are completely inhibited and no cyclization from II to III occurred.

At the opposite, the BOX addressability by $\mathrm{pH}$ change is unaffected by the status of the central DAE and its opening and closure $(\mathbf{I} \rightarrow \mathbf{I I}$ and IV $\rightarrow$ III) can be achieved selectively and quantitatively upon acidification and neutralization of solution respectively. Addressing of BOX opening with light is impeded in acetonitrile solution, but is revealed in the presence of chlorobenzene as photosensitizer and upon $254 \mathrm{~nm}$ light irradiation. Interestingly, the simultaneous opening of both BOX is achieved from irradiation of the state $\mathbf{I},(\mathbf{I} \rightarrow \mathbf{I I})$ whereas the process is successive from irradiation of the state IV (IV $\rightarrow$ III' $\rightarrow$ III). Contrary to previous investigated derivatives joining one DAE and one BOX, the state III is not thermally stable and slowly evolves towards the state II, by decyclization of its DAE part. Such a thermal unstability 
was also encountered with all the states having at least one of the ethylenic junctions in cis isomery.

Beside their photo- and acidochromic properties, BOX moieties are also electroactive and their electrochemical behavior is strongly affected by the status of the central DAE. Oxidation of the targets in their states I conducts to a C-C oxidative coupling for $\mathbf{1}$, while to the simultaneous opening of the oxazolidine ring $(\mathbf{I} \rightarrow \mathbf{I I})$ for methyl-substituted 2 . Such behavior between 1 and $\mathbf{2}$ compound is no longer observed when the central DAE is closed. Indeed, the oxidation occurring mainly on the cyclized DAE in the state IV, leads surprisingly to the selective opening of only one BOX unit (IV $\rightarrow$ III') in both targets. The impossibility to induce the opening of the second BOX was assigned to the oxidation of III' into an $\mathbf{X}$ form already observed on few DAE based compounds, and being under deeper investigation to identify it.

\section{Experimental section}

\subsection{Synthesis of targets}

The synthesis of the targets is pretty straightforward and start by the elaboration of the $4,4^{\prime}-$ bis(2-carboxaldehyde-5-methylthiophene)perfluorocyclopentene from corresponding dichloro derivative according to the procedure described by Feringa et al. [21]. Its further functionalization lays down on the high reactivity of the indoleninium or indolinooxazolidine derivatives with different aromatic aldehydes or nitroso compounds [22]. Hayami et al. reported that the reaction can be performed under several different experimental conditions (protic and aprotic solvents, solvent-free conditions, addition of a base) [23]. Nevertheless, the majority of the reported examples are carried out in boiling alcoholic solvents without any additives and gave satisfactory yields. However in our case, the reflux in ethanol provides the 
diacetal and not the targeted molecules. In order to circumvent this issue, a simple solution consisted to replace the ethanol by a more hindered solvent such as t-butanol. The targets 1 and 2 have been fully characterized by NMR and the ethylenic junctions are both in trans isomery, as confirmed by the two doublets at $6.1(2 \mathrm{H})$ and $6.95(2 \mathrm{H}) \mathrm{ppm}$ with a vicinal scalar coupling of $15.8 \mathrm{~Hz}$.

\subsection{NMR and UV spectroscopies.}

NMR spectra were recorded on Avance Bruker 500 or 300 spectrometer $\left({ }^{1} \mathrm{H}, 500 \mathrm{MHz},{ }^{13} \mathrm{C}\right.$, $125 \mathrm{MHz}$, or ${ }^{1} \mathrm{H}, 300 \mathrm{MHz},{ }^{13} \mathrm{C}, 75 \mathrm{MHz}$ ) equipped with TXI or QNP probe, using standard sequences. Data sets were processed using Bruker Topspin 3.2 software. Samples are dissolved in acetonitrile- $d_{3}$ or in acetonitrile- $d_{3} /$ chlorobenzene- $d_{5}$ in NMR tubes. Photoirradiation was carried out directly into the NMR tube in a home-built apparatus with a 1000W high-pressure $\mathrm{Hg}-\mathrm{Xe}$ lamp equipped with filters. Monochromic UV or visible light was obtained by passing the light through a first filter, then through an interferential one Irradiation with $254 \mathrm{~nm}$ light was achieved in rotating quartz NMR tubes $(5 \mathrm{~mm})$ at $295 \mathrm{~K}$ with a Bioblock Scientific VL-6LC lamp (12 W).

UV-visible spectra were recorded with a Perkin-Elmer lambda 950 spectrophotometer. Photoirradiation were carried out directly into the quartz absorption cuvettes from Hellma using TLC observation lamp allowing to switch between two different UV tubes (8W) purchased from Vilber-Lourmat emitting respectively at 254 and $312 \mathrm{~nm}$.

4.3 Electrochemical experiments. 
Cyclic Voltammetry. Acetonitrile (HPLC grade) and tetra-n-butylammonium hexafluorophosphate (TBAP, electrochemical grade, Fluka was recrystallised from ethanol). Cyclic voltammetry (CV) was performed in a three-electrode cell equipped with a platinum millielectrode, a platinum wire counter-electrode and a silver wire used as a quasi-reference electrode. The voltammograms were recorded on a potentiostat/galvanostat (BioLogic SP150) driven by the EC-Lab software with positive feedback compensation. All the potentials reported were calibrated versus ferrocene/ferrocenium oxidation potential $(+0.405 \mathrm{~V}$ vs SCE or $+0.425 \mathrm{~V}$ vs $\mathrm{Ag} / \mathrm{AgCl})$.

Time-resolved spectroelectrochemistry was performed using the already described experimental setup [24]. The home self-made spectro-electrochemical cell body as well as all the parts are made of Teflon in order to be compatible with a broad variety of solvents. Viton O-rings are used where needed in order to ensure gas-tightness. The working electrode is a c.a $2 \mathrm{~mm}$ diameter disk of polished platinum inserted in a Teflon rod. It is mounted in the central well on a micrometer screw that permits fine adjustment of the distance between the electrode and the optical window, while maintaining the surface of the electrode parallel to the window. It was completed by a platinum wire as counter electrode and a silver wire used as a quasireference electrode. Its potential was checked vs. the ferrocene/ferrocenium couple before and after each experiment. Electrochemical measurements were carried out with a Biologic SP-150 potentiostat driven by the EC-Lab software including ohmic drop compensation. Spectrophotometric measurements were carried out in direct reflexing mode on the working electrode with a homemade bench composed of different Princeton Instruments modules (light sources, fibers, monochromators, spectroscopy camera and software) using a "Y-shaped" optical fiber bundle to connect the light source, the spectroelectrochemical cell and the spectrophotometer 


\section{Supplementary data}

Synthesis, ${ }^{1} \mathrm{H}$ NMR and absorption spectra

\section{Acknowledgements}

This work was financially supported from ANR SIMI 7

\section{References}

[1] Irie M. Diarylethenes for Memories and Switches. Chem Rev 2000;100:1685-1716.

[2] Irie M, Fukaminato T, Matsuda K, Kobatake S. Photochromism of Diarylethene Molecules and Crystals: Memories, Switches and Actuators. Chem Rev 2014;114:12174-12277.

[3] Xiang D, Wang X, Jia C, Lee T, Guo X. Molecular-Scale Electronics: From Concept to Function. Chem Rev 2016;116:4318-4440.

[4] Peters A, Branda NR. Electrochromism in Photochromic Dithienylcyclopentenes. J Am Chem Soc 2003;125:3404-3405.

[5] Browne WR, de Jong JJD, Kudernac T, Walko M, Lucas LN, Uchida K, van Esch JH, Feringa BL. Oxidative Electrochemical Switching in Dithienylcyclopentenes, part 2: Effect of Substitution and Asymmetry on the Efficiency and Direction of Molecular Switching and Redox Stability. Chem Eur J 2005;11:6430-6441.

[6] Browne WR, de Jong JJD, Kudernac T, Walko M, Lucas LN, Uchida K, van Esch JH, Feringa BL. Oxidative Electrochemical Switching in Dithienylcyclopentenes, part 1: Effect of Electronic Perturbation on the Efficiency and Direction of Molecular Switching. Chem Eur J 2005;11:6414-6429.

[7] Sertova N, Nunzi JM, Petkov I, Deligeorgiev T. Photochromism of Styryl Cyanine Dyes in Solution. J Photochem Photobiol A 1998;112:187-190. 
[8] Bartnik R, Lesniak S, Mloston G, Zielinski T, Gebicki K, Cationic Dye Derivatives of 1(2-hydroxyethyl)-2-styryl-3,3-dimethyl- 3H-indole, Chem Stosow 1990;34:325-334.

[9] Bartnik R, Mloston G, Cebulska Z. Synthesis and Chain-ring Tautomerism of 1-(2hydroxyethyl)-3,3-dimethyl-3H-indole Derivative Cyanine dyes. Chem Stosow 1990;34:343-352.

[10] Szaloki G, Aleveque O, Pozzo JL, Hadji R, Levillain E, Sanguinet L. Indolinooxazolidine: A Versatile Switchable Unit. J Phys Chem B 2015;119:307-315.

[11] Oms O, Hakouk K, Dessapt R, Deniard P, Jobic S, Dolbecq A, Palacin T, Nadjo L, Keita B, Marrot J, Mialane P. Photo- and Electrochromic Properties of Covalently Connected Symmetrical and Unsymmetrical Spiropyran-Polyoxometalate Dyads. Chem Commun 2012;48:12103-12105.

[12] Browne WR, Pollard MM, de lange B, Meetsma A, Feringa BL. Reversible ThreeState Switching of Luminescence: A New Twist to Electro and Photochromic Behavior. J Am Chem Soc 2006;128:12412-12413.

[13] Wu Y, Guo Z, Zhu WH, Wan W, Zhang J, Li W, Li X, Tian H, Li ADQ. Photoswitching between black and colourless spectra exhibits resettable spatiotemporal logic. Mater Horiz 2016;3:124-129.

[14] Zhu W, Song L, Yang Y, Tian H. Novel Bisthienylethene Containing Ferrocenyl Substituted Naphthalimide: Photo- and Redox Multi-addressable Molecular Switch. Chem Eur J 2012;18:13388-13394

[15] Kawami S, Yoshioka H, Nakatsu K, Okazaki T, Hayami M. X-Ray Structures of Electrochromic Compounds, Colorless 3,3-Dimethyl-2-(p-dimethylaminostyryl)indolino[1,2-b]oxazoline and Colored 2-(p-Dimethylaminostyryl)-1-hydroxyethyl-3,3dimethylindolinium Bromide. Chem Lett 1987;16: 711-714. 
[16] Sanguinet L, Pozzo JL, Rodriguez V, Adamietz F, Castet F, Ducasse L, Champagne B. Acido- and Phototriggered NLO Properties Enhancement. J Phys Chem B $2005 ; 109: 11139-11150$.

[17] Sevez G, Gan J, Delbaere S, Vermeersch G, Sanguinet L, Levillain E, Pozzo JL. Photochromic performance of a dithienylethene-indolinooxazolidine hybrid. Photoch Photobio Sci 2010;9:131-135.

[18] Szaloki G, Sevez G, Berthet J, Pozzo JL, Delbaere S. A Simple Molecule-Based Octastate Switch. J Am Chem Soc 2014;136:13510-13513.

[19] Sanguinet L, Delbaere S, Berthet J, Szaloki G, Jardel D, Pozzo J-L. Dithienylethenebased gated ambichromic dyads. Adv Opt Mater 2016;4:1358-1362.

[20] Hadji R, Szaloki G, Aleveque O, Levillain E, Sanguinet L. The stepwise oxidation of indolino[2,1-b]oxazolidine derivatives. J Electroanal Chem 2015;749:1-9.

[21] Lucas LN, van Esch J, Kellogg RM, Feringa BL. A new synthetic route to symmetrical photochromic diarylperfluorocyclopentenes. Tetrahedron Lett 1999;40:1775-1778.

[22] Szaloki G, Sanguinet L. The properties and application of indolinooxazolidines as photo-, electro- and acidochromic. Yokoyama Y, Nakatani K, editors. Photon-Working Switches.:Springer; 2016, in press

[23] Hayami M, Torikoshi S. Color-changing compounds. DE2541666A1 1976.

[24] Aleveque O, Levillain E, Sanguinet L. Spectroelectrochemistry on electroactive selfassembled monolayers: Cyclic voltammetry coupled to spectrophotometry. Electrochem Comm 2015;51:108-112. 
Highlights

- A diarylethene joined to two benzooxazolidine by ethylenic spacers was synthesized

- Photochromic, acidochromic and electrochromic responses were evidenced

- The system is multistate (among the 18 possible states, 13 were underlined)

- The system is multifunctional (same interconversion performed by different stimuli) 